\title{
CORRIGENDUM
}

Genes \& Development 18: 2237-2242 (2004)

\section{Corrigendum: In vivo investigation of the transcription, processing, endonucleolytic activity, and functional relevance of the spatial distribution of a plant miRNA}

Eneida Abreu Parizotto, Patrice Dunoyer, Nadia Rahm, Christophe Himber, and Olivier Voinnet

Figure 1B was a composite made of two segments extracted from the same RNA blot, but this operation was not indicated on the original figure. In addition, in retrieving the digital data used for the loading control, we realized that the loading order of the corresponding preparatory agarose gel was inverted compared with the loading of the samples in the Northern blot. We have now corrected the figure to disclose the gel splicing procedure by separating the samples appropriately, which are also now shown with their cognate rRNA loading control, taking into account the inverse loading.

Figure $3 \mathrm{O}$ was a composite of segments extracted from the same RNA blot, but this operation was not indicated on the original figure. We have now corrected the figure to disclose the gel splicing procedure by separating the samples appropriately. In addition, the amended figure now displays ethidium bromide staining of rRNA from the original formamide gel used for Northern blotting instead of the nonerroneous preparatory agarose gel depicted in the initial figure.

The protein loading controls of the Western blots originally depicted in Figure 1, E and F, and Supplemental Figure S3B have been mixed up. In addition, the noninfiltrated (ni) negative control track of Figure $1 \mathrm{~F}$ was incorrect and should have been separated from the experimental data with a line. We have now corrected Figure $1 \mathrm{~F}$ to disclose the gel splicing procedure by separating the samples appropriately and have assigned the correct protein loading controls to the corresponding tracks of the Western blots displayed in Figure 1, E and F, and Supplemental Figure S3B.

All of the corrections were made based on the original raw data provided to the editors. The errors did not alter the data in any material way that could be construed to benefit the authors, and the conclusions drawn from these data remain unaffected. The corresponding author, Olivier Voinnet, takes full responsibility for the mistakes, as none of the other authors was involved in the final mounting of the figures.

doi: $10.1101 / \operatorname{gad} .283721 .116$
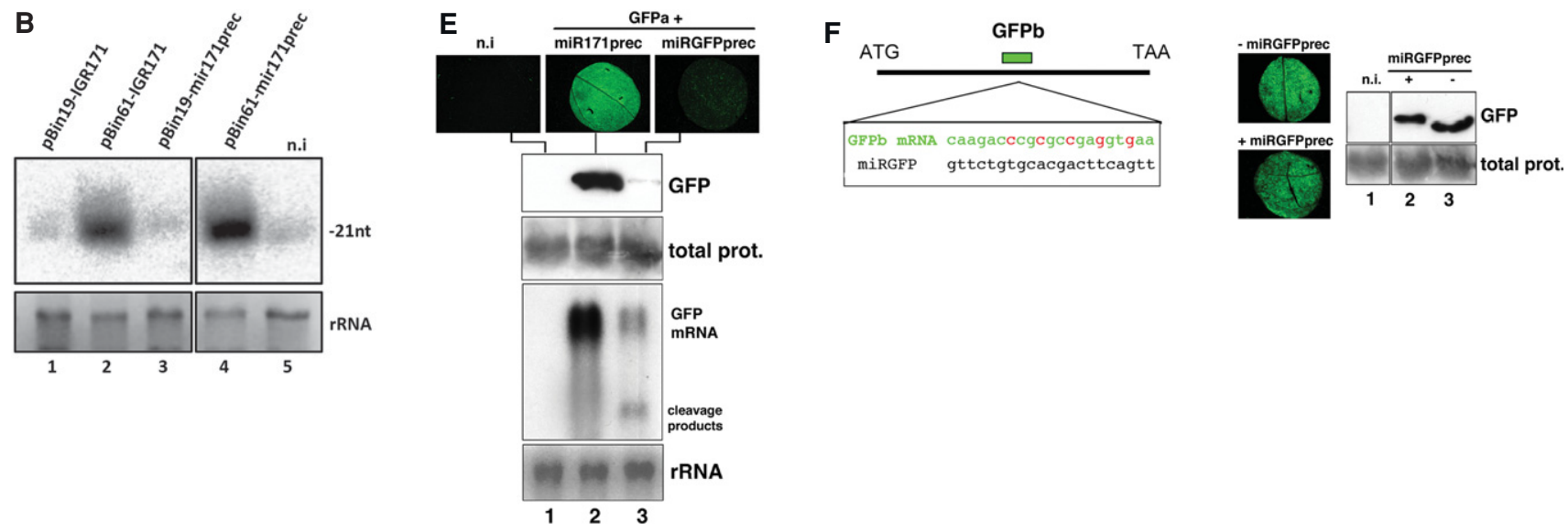

Figure 1. 
0

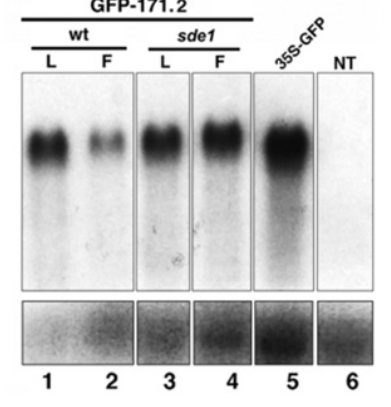

Figure 3.

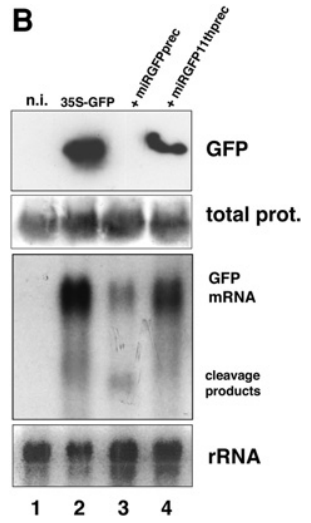

Supplemental Figure S3. 


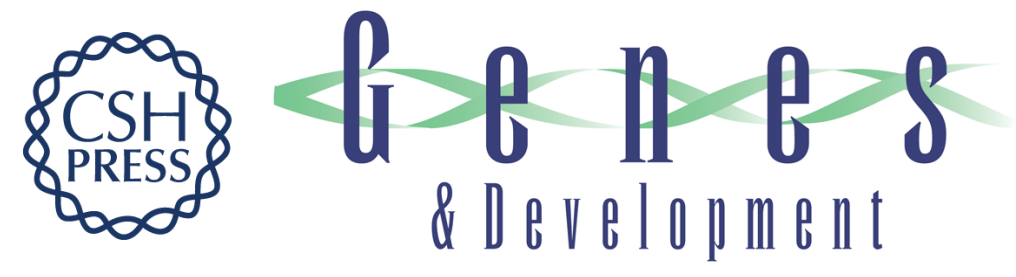

\section{Corrigendum: In vivo investigation of the transcription, processing, endonucleolytic activity, and functional relevance of the spatial distribution of a plant miRNA}

Eneida Abreu Parizotto, Patrice Dunoyer, Nadia Rahm, et al.

Genes Dev. 2016, 30:

Access the most recent version at doi:10.1101/gad.283721.116

Related Content In vivo investigation of the transcription, processing, endonucleolytic activity, and functional relevance of the spatial distribution of a plant miRNA

Eneida Abreu Parizotto, Patrice Dunoyer, Nadia Rahm, et al.

Genes Dev. September , 2004 18: 2237-2242

\section{License}

Email Alerting

Service

Receive free email alerts when new articles cite this article - sign up in the box at the top right corner of the article or click here.

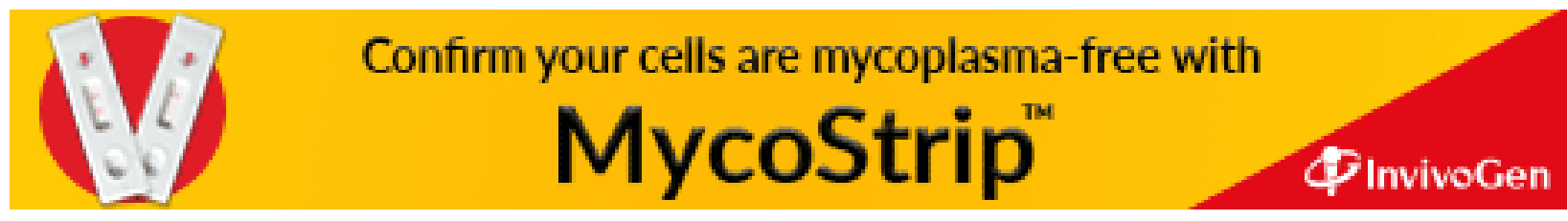

